\title{
MODELO DE GESTÃO DAS BARBEARIAS MODERNAS
}

FONSECA, David ${ }^{1}$;

PESSOA, Marcelo² - id https://orcid.org/0000-0002-9193-4604

DOI NUMBER: 10.33726/akedia2447-7656v7a52019p159-164

RESUMO: Este estudo tem o objetivo de demonstrar o modo como o negócio de barbearias tem se desenvolvido ao longo dos anos, e como se posiciona no mercado contemporâneo. Com este intuito, então, se buscou compreender alguns dos desafios que se impõem aos gestores, tentando-se identificar o modo como se pode agregar diferentes produtos e serviços em um tipo de negócio tradicional. Do mesmo modo, procuramos entender parte do processo que levou este empreendimento migrar do segmento meramente estético, chegando ao patamar de treinamentos mais éticos e profissionais. Esta pesquisa está sendo desenvolvida por meio de uma metodologia essencialmente de revisão bibliográfica.

PALAVRAS-CHAVE: Barbearia, setor de estética, empreendimento.

ABSTRACT: This study aims to demonstrate how the business of Barber shops has developed over the years, and as positioned contemporary. With this intention, then, if sought to understand some of the challenges require managers, trying to identify the way in which we can add different products and services in a kind of traditional business. Likewise, sought to understand part of the process that led this project to migrate from aesthetic purposes segment, reaching the level of more ethical and professional training. This research is being developed through a methodology of literature review.

KEYWORDS: Barber Shop, beauty industry, Enterprise.

\section{INTRODUÇÃO}

Em função de ser conhecedor do histórico desse tipo de empreendimento denominado "barbearias", face ao envolvimento familiar deste autor com o ramo citado, é que se desenvolveu o interesse de iniciar algum tipo de pesquisa que tratasse deste assunto.

Já, durante o levantamento de dados bibliográficos em repositórios digitais, não me foi muito difícil notar que esta já foi tida como uma das

Discente do Curso de Administração, da UEMG, Unidade Frutal - MG. Contato: kyemanubarbersop@gmail.com.

${ }^{2}$ Docente titular da cadeira de Língua Portuguesa, na UEMG - Unidade Frutal. 
profissões mais comuns durante a Idade Media, geralmente fornecendo cuidados destinados ao tratamento de soldados durante ou após as batalhas.

É curioso o fato que, dentre os cuidados estéticos acionados pelo "barbeiro" da Idade Média, também estiveram a realização de pequenas cirurgias, sangrias, extração de dentes etc. Por essa razão é que o "barbeiro" medieval ficou conhecido por meio dos relatos históricos como "barbeiro cirurgião":

Com o avançar do conhecimento acadêmico, os barbeiros-sangradores foram se especializando em trabalhos menos invasivos e mais focados no aspecto estético, deixando de lado, gradualmente, as chamadas "artes populares de cura" (COSTA, 2018, p. 01).

Após o século XVII, com o desenvolvimento das várias áreas do conhecimento, a ciência médica moderna tomou o lugar dos barbeiros, os quais, desde então, passaram a se dedicar apenas aos cuidados de higiene ou estéticos com a barba e com os cabelos masculinos, iniciando-se, com isso, os princípios da cosmetologia.

Com o passar dos tempos, foi natural que o segmento "barbeiro" ou "barbearias" fossem perdendo seu espaço no âmbito do comércio.

E foi assim, que a barbearia e os barbeiros, do modo como os conhecemos, chegam novamente aos tempos contemporâneos, renovados e revestidos com "túnicas gourmetizadas", oferecendo diferentes tipos de serviços aos clientes, modernizando seus modos de serem realizados, ao mesmo tempo em que atuam reinserindo em suas práticas antigos ritos de assepsia, de higiene e de descarte de instrumental utilizado, higienizando seus locais de trabalho, deixando-os tão limpos, iluminados e vistosos como se fossem hospitais, posturas que, de certo modo, rememoram no barbeiro moderno o antigo "cirurgião barbeiro" medieval. 


\section{COMO ESTE TIPO DE EMPRESA ATUA NO MERCADO}

Tem-se como lema, a ideia de que a barbearia é uma grande família. Consequentemente, diz-se que a empresa é casa daqueles que nela trabalham. Logo, os colaboradores da empresa são os familiares, e os clientes são os parentes que periodicamente visitam este lar.

É assim que o segmento "barbearia" atua, de forma harmoniosa, a fim de que se desenvolvam, do melhor modo o quanto possível, todos os tipos de serviços constantes do mix de produtos do negócio instalado.

Vale dizer ainda, que é bastante recorrente $o$ fato de que os empreendedores do ramo de barbearias, especialmente na contemporaneidade recente, buscarem diversas alternativas para melhoria da empresa e inovação no médio e longo prazo, instituindo-se, para isso, Planos de Negócios bem elaborados e conduzidos pelos respectivos gestores.

Estes Planos de Negócios, além dos aspectos tradicionais exigíveis pelo mercado financeiro, também contemplam elementos mais gerais, tais como a transição da reconfiguração de uma imagem externa e interna da empresa, quando ainda detentora de características antigas, aparentando ser barbearia uma do "passado", prevendo-se, desse modo, uma intensa modernização das instalações, cobrindo itens de climatização, aconchego, paisagismo e bem estar.

Outro item que também se tem feito constar nos Planos de Negócio, diz respeito à capacitação profissional dos stakeholders. Com isso, tem-se melhorado substancialmente o nível do atendimento e o teor qualitativo das funções gerenciais, tais como eficácia produtiva, organização, marketing etc., consubstanciando-se, assim, o perfil geral do que hoje se denominam como a "Barbearia Moderna". 
Enfim, podemos dizer que esta modalidade de empresa tende a ser constituída não apenas a partir de produtos ou serviços mais tradicionais ao ramo, mas, sobretudo, de técnicas de conduta ideologicamente pautadas para que não se misture o passado com o presente, evitando-se que se realize um processo imperceptível e doloroso de descontinuidade contábil.

No ramo da estética masculina atribuindo ao cliente confiança e conforto e sempre na fidelização com intuito de que o cliente não se sinta na obrigação de volta mais sim com vontade de sempre volta com satisfação no que lhe foi oferecido.

\section{ITENS GERAIS DE INSTALAÇÃO, FUNCIONAMENTO E PÚBLICOS DA EMPRESA}

Este tipo de negócio pode ser regido a partir de seu próprio escritório, montado nas dependências da própria empresa. Ali se desincumbem as funções de gestão das finanças, se desenvolvem novos projetos, se realizam treinamentos, se fazem contratações de pessoal e se operam as ações de marketing.

O tópico marketing, por sua vez, é um ponto bastante sensível deste tipo de empreendimento. O gestor do negócio, que pode ser o próprio dono, precisa ser um tipo de pessoa formada ou familiarizada com as mídias modernas de comunicação.

Desse modo, é interessante que ele domine os vieses e reveses do sistema, implantando constantemente ótimas ideias de promoção e propaganda da empresa, divulgando os produtos e serviços nas redes sociais, promovendo e inovando em regime de fluxo contínuo (SEBRAE, 2018).

O segmento de barbearias, nos últimos anos, tem passado a disponibilizar aos clientes mais do que cortes de cabelo e barba. Tem-se 
ofertado trabalhos de design de sobrancelhas, limpezas de pele, massagens corporais, vendas de produtos e demais acessórios estéticos, além de ministrar cursos profissionalizantes para adultos, jovens, crianças e idosos de ambos os sexos, que desejem se tornar novos barbeiros e afins.

Um dos principais focos na formação dos novos empreendedores do ramo tem sido o de prepara-los para que tratem os clientes e seus colaboradores sempre com seriedade e respeito, cumprindo suas devidas tarefas e metas, obtendo-se, com isto, crescimento profissional e ético, aumentando a credibilidade comercial da empresa e de seus colaboradores.

\section{CONCLUSÃO}

Conclui-se com este breve estudo, que, o fato de já existirem/várias empresas nesse ramo, não basta para que se consolide ininterruptamente o nicho de clientes. Confiança e credibilidade são valores que precisam constantemente de retroalimentação.

Por isso, se faz cada vez mais importante o planejamento de boas estratégias e a execução de novos projetos.

Do mesmo modo, é cada vez mais imprescindível o treinamento de equipes, de gestores, formando um time de pessoas dispostas, inovadoras, que tenham ótimas relações umas com as outras, aumentando o nível de credibilidade do negócio junto aos públicos envolvidos. 


\section{REFERÊNCIAS}

COSTA, Pedro H. A história da barbearia como profissão de saúde. Disponível em: Universo Racionalista, 2018: https://universoracionalista.org/a-historia-da-barbeariacomo-profissao-de-saude/. Acesso em 27/03/2019.

SALIM, Cesar Simões (et al). Construindo Planos de Negócios - todos os passos necessários para planejar e desenvolver negócios de sucesso. Rio de Janeiro: Elsevier, 2005.

SEBRAE. Relatório de Inteligência. Beleza e Bem-Estar. Mercado de Beleza Masculina, 2018. Disponível em: file:///C:/Users/User/Downloads/9eae691b-0b824229-9d0d-1ecd5bde48b5.pdf. Acesso em: 27/03/2019. 